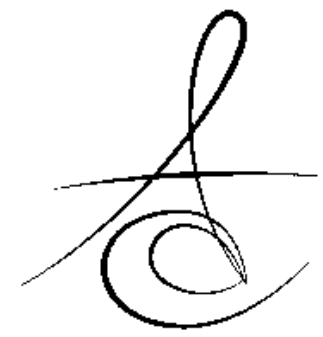

\title{
DENTAL İMPLANT UYGULAMALARINDA KARŞILAŞILAN İNTRAOPERATİF VE ERKEN DÖNEM KOMPLİKASYONLARIN PREVALANSI VE TEDAVİ YÖNTEMLERİ: RETROSPEKTİF KLİNİK ÇALIŞMA PREVALENCE AND TREATMENT METHODS OF INTRAOPERATIVE AND EARLY COMPLICATIONS IN DENTAL IMPLANT SURGERY: A RETROSPECTIVE CLINICAL STUDY
}

\section{Dr. Öğr. Üyesi Gelengül URVASIZOĞLU*}

Arş. Gör. Dt. Tuğrul TÜREN*

Makale Kodu/Article code: 3835

Makale Gönderilme tarihi: 18.10 .2018

Kabul Tarihi: 18.12 .2018

\section{öz}

Amaç: Bu çalışmanın amacı; rutin implant uygulamalarında kliniğimizde karşılaşılan intraoperatif ve erken dönem komplikasyon türlerinin, sayı ve oranlarının araştırıması ve komplikasyon yönetiminde uygulanan tedavilerin değerlendirilip akademisyenler ve klinisyenler için aydınlatıcı ve yol gösterici olmaktır.

Gereç ve Yöntem: Bu çalışmada; Atatürk Üniversitesi Diş Hekimliği Fakültesi Ağız Diş ve Çene Cerrahisi Anabilim Dalında 2015-2018 yılları arasında 138 hastada uygulanan 498 adet implant retrospektif olarak değerlendirildi. Çalışma süresince implant tedavisi uygulanan hastaların arşiv kayıtları ve ameliyat notları incelendi. Aralarından kayıtları eksiksiz tutulan ve takip seanslarına düzenli olarak devam eden hastalar seçilerek, intraoperatif ve erken dönem komplikasyonları ve prevelansları belirlenip uygulanmış olan tedavi yöntemleri araştırıldı.

Bulgular: Çalışma kapsamında dental implant cerrahilerinde intraoperatif ve erken dönem postoperatif komplikasyonlar belirlenmiştir. İnceleme sonucunda komplikasyon oranlarının $\% 0$ ile \%34 arasında değiştiği izlenmiştir. Karşılaşılan intraoperatif komplikasyon oranları ve türleri sırasıyla; yumuşak doku yaralanmaları $(\% 4,3)$, alveoler kemikte dehissens/ fenestrasyon(\%2), nasal kavite/sinüs perforasyonları(\%1,1), sinir yaralanmaları $(\% 0,8)$, komşu diş hasarı $(\% 0,4)$, damar yaralanmaları $(\% 0,2)$ ve primer stabilite kaybıdır(\%0,2). Erken dönem post operatif komplikasyonlar ise; ödem(\%34), ekimoz/hematom $(\% 10,1)$, his kaybı $(\% 3,06)$, enfeksiyon $(\% 1,6)$, yara yerinin açıması $(\% 1,1)$, kanama( $\% 0,7)$ olarak izlenmiştir.

Sonuç: Dental implant cerrahileri her zaman komplikasyona açık, küçümsenmemesi gereken cerrahilerdir. Karşılaşılan komplikasyonlar dikkatle değerlendirilmeli ve anında müdahale edilmelidir. Başarılı bir implant tedavisi için; iyi bir anamnez, doğru tedavi planlaması, uygun hasta seçimi ve yeterli komplikasyon yönetebilme bilgisi ve becerisi gerekmektedir.

Anahtar Kelimeler: Diş implantı, intraoperatif komplikasyonlar, postoperatif komplikasyonlar

\section{ABSTRACT}

Aim: The aim of this study; evaluation of the types, quantities and rates of intraoperative and early complications encountered in our clinic during routine implant surgeries and investigating the treatments used in complication management, also for academicians and clinicians to be illuminating and guiding in terms of complications.

Material and Metods: This study was carried out retrospectively in Atatürk University Faculty of Dentistry Department of Oral and Maxillofacial Surgery on 498 implants operated on 138 patients between 2015 and 2018. Archival records and operative notes of patients undergoing implant therapy during the study period were reviewed. Patients with thorough records and continuing follow-up sessions were selected and their intraoperative and early complications and incidences were determined and evaluated.

Results: In this study, intraoperative and early postoperative complications were determined in dental implant surgeries. The complication rates in this study ranged from $\% 0$ to $\% 34$. The rates of intraoperative complications encountered are as follows; soft-tissue injuries(\%4,3), dehiscence/fenestration in the alveolar bone $(\% 2)$, nasal cavity/sinus perforations $(\% 1,1)$, nerve injuries $(\% 0,8)$, neighbor tooth damage $(\% 0,4)$, vascular injuries $(\% 0.2)$ and lack of prime stability $(\% 0.2)$. Early postoperative complication rates are; edema(\%34), ecchymosis/hematomes(\%10.1), sensory disorders(\%3.06), infection(\%1.6), flep dehiscence(\%1.1), bleeding(\%0.7).

Conclusion: Dental implant surgeries are always open to complications that should not be underestimated. Complications should be carefully evaluated and intervened with immediately. For a successful implant treatment; a detailed anamnesis, proper treatment planning, appropriate patient selection and sufficient knowledge and skill to manage complications are required.

Keywords: Dental implant, intraoperative complications, postoperative complications

\footnotetext{
* Atatürk Üniversitesi Diş Hekimliği Fakültesi Ağız Diş Ve Çene Cerrahisi AD, Erzurum.
} 


\section{GİRİŞ}

Günümüzde dental implant uygulamaları eksik dişlerin rehabilitasyonunda en çok tercih edilen tedavi yöntemlerinden biri haline gelmiştir. ${ }^{1}$ Bunun sebebi; kaybedilen doğal dişlerin yerine konmasında estetik ve fonksiyon açısından hastaların beklentilerini karşılayabilen modern bir seçenek olmasıdır. ${ }^{2}$ Dental implant uygulamaları yüksek başarı oranlarına sahip olmasına rağmen birçok komplikasyona da açık cerrahi girişimlerdir ve bu komplikasyonlar nadir sayılamayacak düzeylerdedir. ${ }^{3}$

Komplikasyonların yönetimini ve tedavilerini daha anlaşılır hale getirmek ve açıklayabilmek için araştırmacılar birçok sınıflama yapmışlardır. Annibali ve ark. $^{4}$ yaptıkları sınıflamada; kaza ve komplikasyon olarak iki ayrı terim tercih etmişlerdir. Cerrahi işlem sırasında gerçekleşen sorunlara kaza terimini kullanırken, komplikasyon terimini ise implantın yerleşimden takip sürecine kadar olan tüm problemleri tanımlamak için kullanmışlardır. Bunların yanında komplikasyon kavramını da erken dönem ve geç dönem komplikasyonlar olarak iki alt başlığa ayırmışlardır. (Tablo 1) Komplikasyonların gerçekleşme zamanı dışında türü ile ilgili olarak da Annibali bu problemleri; (1) fonksiyonel kemik kaybı, (2) gingival komplikasyonlar ve (3) mekanik komplikasyonlar olarak üç ana tipe ayırmıştır. Balshi ${ }^{5}$, dental implant tedavileri sırasında ortaya çıkan sorunların önlenmesi ve tedavisi ile ilgili çalışmasında sadece komplikasyon terimi kullanarak sınıflama yapmıştır. Komplikasyonları altı kategoriye ayırarak; estetik, fonetik ve işlevsel komplikasyonlar (protetik restorasyon aşamasında); biyolojik ve mekanik komplikasyonlar (materyallerin ağız boşluğundaki kuvvetleri uygun bir şekilde karşılayamaması) ve ergonomik komplikasyonlar (cerrahın deneyimsizliğinin bir sonucu olarak tedavinin herhangi bir aşamasında ortaya çıkar) olarak özetlemiştir. Park ve ark. ${ }^{6}$ ise komplikasyon sınıflamasını intraoperatif ve postoperatif komplikasyonlar olarak iki başlık altında toplamıştır.

Dental implant uygulama prosedürleri sırasında veya postoperatif takiplerde çoğu zaman beklentiler dahilinde hiçbir komplikasyon veya istenmeyen durumla karşılaşılmadan tedavi gerçekleştirilir. Bununla birlikte; intraoperatif ve postoperatif komplikasyonlarla karşılaşılabileceği göz ardı edilmemelidir. Tedaviler sırasında gerçekleşebilecek potansiyel sorunları anlayabilmek ve onlardan uzak duracak bilgiye sahip olmak etkili tedaviyi kolaylaştırır. Benzer şekilde, beklenmedik durumları tanıma ve yönetme becerisine sahip olmak dental implant hizmetleri sunan hekimler için mutlak gerekli nitelikler arasındadır. ${ }^{7}$

Tablo 1. İntraoperatif ve postoperatif erken dönem komplikasyonlar

\begin{tabular}{|l|l|}
\hline $\begin{array}{l}\text { İntraoperatif } \\
\text { Komplikasyonlar }\end{array}$ & $\begin{array}{l}\text { Erken Dönem } \\
\text { Komplikasyonalar(0-1 Hafta) }\end{array}$ \\
\hline Yumuşak doku yaralanmaları & Enfeksiyon \\
\hline Damar yaralanmaları & Ödem \\
\hline Sinir yaralanmaları & Ekimoz/Hematom \\
\hline $\begin{array}{l}\text { Nasal kavite/Sinüs } \\
\text { perforasyonları }\end{array}$ & Amfizem \\
\hline $\begin{array}{l}\text { Alveoler kemikte } \\
\text { dehissens/fenestrasyon }\end{array}$ & Kanama \\
\hline Komşu diş hasarı & Yara yerinin/Flebin açılması \\
\hline Enstrüman kırılması & His kaybı \\
\hline Enstrüman yutma/aspirasyon & \\
\hline Primer stabilite kaybı & \\
\hline
\end{tabular}

$\mathrm{Bu}$ çalışmanın amacl; rutin implant uygulamalarında kliniğimizde karşılaşılan intraoperatif ve postoperatif erken dönem komplikasyon türlerinin, sayı ve oranlarının araştırıması ve komplikasyon yönetiminde uygulanan tedavilerin değerlendirilip akademisyenler ve klinisyenler için aydınlatıcı ve yol gösterici olmaktır.

\section{GEREÇ VE YÖNTEM}

Bu çalışmada; Atatürk Üniversitesi Diş Hekimliği Fakültesi Ağız Diş ve Çene Cerrahisi Anabilim Dalında 2015-2018 yılları arasında 138 hastada uygulanan 498 adet implant retrospektif olarak değerlendirildi. Hasta grubunun tamamı sağlıklı veya mevcut sistemik rahatsızlıkları (diyabet, hipertansiyon vb.) kontrol altına alınmış durumda olan hastalardan oluşmaktadır. Çalışmaya verileri intraoperatif ve erken dönem olarak eksiksiz biçimde tutulan ve radyografileri bulunan hastalar dahil edilmiştir. Araştırma ile intraoperatif olarak; yumuşak doku yaralanmaları, damar yaralanmaları, sinir yaralanmaları, nasal kavite ve sinüs perforasyonları, komşu diş hasarı, enstrüman kırılması, enstrüman yutulması veya aspirasyonu ve primer stabilite kaybı değerlendirilmiştir. Erken dönem komplikasyonlarda ise; enfeksiyon, ödem, ekimoz, hematom, amfizem, kanama, flep açılması ve duyusal bozukluklar değerlendirilip tüm bu komplikasyonların verileri ile birlikte uygulanan tedavi yöntemleri araştırılmıştır.

Literatürdeki araştırmalar göz önüne alınarak her bir komplikasyonun oranı hesaplanırken

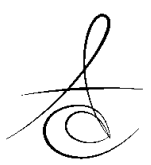


komplikasyon türüne bağlı olarak hasta sayısı, implant sayısı veya flep sayısı baz alınmışıı. Yumuşak doku yaralanmaları, his kaybı (mandibulaya implant uygulanan hasta sayısI), ödem, ekimoz/hematom, amfizem ve kanama komplikasyonları için hasta sayısı; yara yerinin açımasının prevelansı hesaplanırken açılan flep sayısı hesaba katılmışıı. Ayrıca nasal kavite ve sinüs perforasyonları için sadece maksillaya, sinir yaralanmaları için ise sadece mandibulaya uygulanan implant sayıları kriter iken diğer komplikasyonlar için ise toplam implant sayıları değerlendirmeye alınmıştır. ${ }^{3, ~ 8-11}$

Çalışmada, implant tedavisi uygulanan hastaların ameliyat notları ve arşiv kayıtları incelenmiştir. Aralarından kayıtları eksiksiz tutulan ve takip seanslarına devam eden hastalar seçilerek intraoperatif ve erken dönem komplikasyonları ve prevelansları belirlenip uygulanmış olan tedavi yöntemleri değerlendirilmiştir.

\section{BULGULAR}

Bu çalışmada; yaşları 18 ile 72 arasında değişen 138 hasta (76 kadın, 62 erkek) ve lokal anestezi altında uygulanan 498 adet kemik içi dental implant değerlendirilmiştir. Uygulanan implantların cinsiyete ve uygulanan çeneye göre hasta sayısı ve implant sayısı dağııımı Tablo 2'de gösterilmiştir.

Tablo 2. Cinsiyetlere göre hasta sayıları ve implant dağılımları

\begin{tabular}{|l|l|l|l|}
\hline & Kadın & Erkek & Toplam \\
\hline Hasta Sayısı (n) & 76 & 62 & 138 \\
\hline İmplant Sayısı (n) & 268 & 230 & 498 \\
\hline $\begin{array}{l}\text { Mandibulaya İmplant Yapılan Hasta } \\
\text { SayıSı }\end{array}$ & 47 & 51 & 98 \\
\hline $\begin{array}{l}\text { Maksillaya İmplant Yapılan Hasta } \\
\text { SayıSı }\end{array}$ & 46 & 43 & 89 \\
\hline Mandibulaya Yapılan İmplant Sayısı & 121 & 116 & 237 \\
\hline Maksillaya Yapılan İmplant SayıSı & 147 & 114 & 261 \\
\hline
\end{tabular}

İntraoperatif olarak karşılaşılan komplikasyonlar ve oranları Tablo 3'te gösterilmiştir. İntraoperatif en fazla karşılaşılan komplikasyon \%4,3 ile flep kaldırılırken laserasyona bağlı yumuşak doku yaralanmaları olmuştur. Ardından horizontal kemik yetersizliğine bağlı gelişen alveoler kemikte fenestrasyon ve dehissens oranı \%2 olarak görülmektedir. Açığa çıkan implant yüzeylerine hayvan kaynaklı veya otojen kaynaklı kemik grefti uygulanarak flepler primer olarak kapatılmıştır. Ardından yetersiz vertikal alveoler kret yüksekliğine ve açık ve kapalı sinüs lift işlemlerine bağı olarak gelişen maksiller sinüs ve nasal kavite perforasyonu $\% 1,1$ oranında görülmüştür. Hastalara toplam 17 adet kapalı sinüs lift, 7 adet açık sinüs lift uygulanmışır. Perforasyon bulunan bölgeler membran ile kapatılarak greftleme gerekliyse yapilıp implantlar yerleştirilmiştir. İki hastada ise hastaların frezleme işlemi esnasında ani hareketlerine bağlı olarak mandibular sinir hasarı meydana gelmiştir. Frezlenen implant yuvalarına kanaldan uzak pozisyonda olacak uzunlukta implantlar yerleştirilerek hastalar takip edilmiştir. İki hastada da parestezi gelişmiş olup sadece B vitamini takviyesi ile 6 aylık takip sonucunda parestezinin tamamen geçtiği izlenmiştir. Damar yaralanması ise palatinal bölge diseksiyonuna bağlı olarak palatinal arteriollerde meydana gelmiştir. Kanama tampon ile kontrol altına alınarak operasyona devam edilmiştir. Ayrıca uygulama esnasında 2 hastada komşu diş hasarıyla karşılaşılmışır. Bir tanesi yanlış açılama diğeri ise dar meziodistal genişlik nedeniyle meydana gelmiştir. İlgili dişler ağrı semptomu verdiği için kanal tedavisi uygulanarak takip edilmiştir. Bir adet implantta ise kemik densitesine bağlı olarak primer stabilite kaybı yaşanmışırı. Bu implant çıkartılarak yerine daha geniş çapa sahip bir implant yerleştirilip primer stabilite sağlanmıştır. Bunların dışında intraoperatif komplikasyonlar arasında sayılan; enstrüman kırıması, enstrüman yutulması ve aspirasyonu ile çalışma kapsamında karşılaşılmamışır.

Tablo 3. İntraoperatif komplikasyon sayıları ve oranları

\begin{tabular}{|l|c|c|}
\hline İntraoperatif Komplikasyonlar & $\begin{array}{c}\text { Komplikas- } \\
\text { yon Sayısı }\end{array}$ & Yüzdesi \\
\hline Yumuşak doku yaralanmaları & 6 & $\% 4,3$ \\
\hline Damar yaralanmaları & 1 & $\% 0,2$ \\
\hline Sinir yaralanmaları & 2 & $\% 0,8$ \\
\hline Nasal kavite/Sinüs perforasyonları & 3 & $\% 1,1$ \\
\hline Alveoler kemikte dehissens/fenestrasyon & 12 & $\% 2$ \\
\hline Komşu diş hasarı & 2 & $\% 0,4$ \\
\hline Enstrüman kırıması & 0 & $\% 0$ \\
\hline Enstruman yutma/aspirasyon & 0 & $\% 0$ \\
\hline Primer stabilite kaybı & 1 & $\% 0,2$ \\
\hline
\end{tabular}

Postoperatif erken dönem komplikasyon oranları ise Tablo 4'te verilmiştir. En fazla görülen komplikasyon cerrahi müdahaleye bağlı olarak gelişen ödem olarak ortaya çıkmışıı. Ödemden sonra ise ekimoz en fazla görülen komplikasyondur. Oluşan ödem ve ekimoza implant sayısının etkisinin daha rahat anlaşılması amacıyla tek seansta $3^{\prime}$ ten az ve 3 'ten fazla implant uygulanan hastalar ayrı olarak da değerlendirilmiştir. Ödem ve ekimoz için herhangi bir 
tedavi uygulama gerekliliği yokken antikoagülan tedavi gördüğünü anamnezinde belirtmeyen 1 hastada postoperatif kanama ve hematom ile karşılaşılmışıı (Resim 1). Hasta hospitalize edilerek tedavi edilmiştir.

Tablo 4. Postoperatif erken dönem komplikasyon sayıları ve oranları

\begin{tabular}{|c|c|c|}
\hline $\begin{array}{c}\text { Erken Dönem } \\
\text { Komplikasyonlar }\end{array}$ & Komplikasyon Sayısı & Yüzdesi \\
\hline Enfeksiyon & 8 & $\% 1,6$ \\
\hline \multirow[t]{3}{*}{ Ödem } & $\begin{array}{c}9 \text { (3 İmplant ve altında } 65 \\
\text { hasta) }\end{array}$ & $\% 13$ \\
\hline & $\begin{array}{c}38 \text { (3 implanttan fazla } 73 \\
\text { hasta) }\end{array}$ & $\% 52$ \\
\hline & 47 (Toplam 138 hasta) & $\% 34$ \\
\hline \multirow[t]{3}{*}{ Ekimoz/Hematom } & $\begin{array}{c}2 \text { (3 İmplant ve altında } 65 \\
\text { hasta) }\end{array}$ & $\% 3,07$ \\
\hline & $\begin{array}{c}2 \text { (3 implanttan fazla } 73 \\
\text { hasta) }\end{array}$ & $\% 16,4$ \\
\hline & 14 (Toplam 138 hasta) & $\% 10,1$ \\
\hline Amfizem & 0 & $\% 0$ \\
\hline Kanama & 1 & $\% 0,7$ \\
\hline $\begin{array}{c}\text { Yara yerinin/Flebin } \\
\text { açılması }\end{array}$ & 3 & $\% 1,1$ \\
\hline His kaybı & 3 & $\% 3,06$ \\
\hline
\end{tabular}
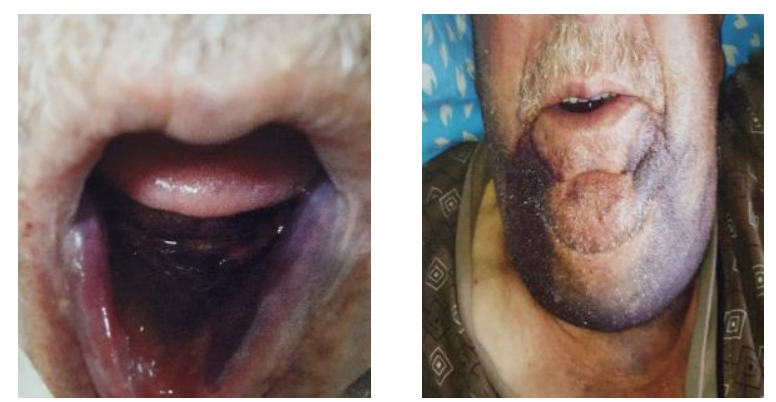

Resim 1. Postoperatif Hematom

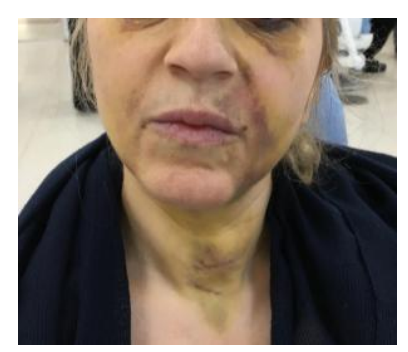

Resim 2. Postoperatif ekimoz

Yerleştirilen implantların 8 tanesinde enfeksiyon meydana gelmiştir. Enfeksiyon gelişen bölgeler antiseptik ajanla irrige edilip antibiyoterapi başlanmıştır. Üç hastada ise flep açılmış olup yara kenarları deepitelize edilerek tekrar suture edilmiştir. Farklı üç hastada ise sinir hasarına bağı his kaybı gelişmiştir.
His kaybı meydana gelen hastalara sadece B vitamini takviyesi verilip takip edilmiştir. Takipler sonucunda 6 ay içerisinde parestezinin ve sinir trasesindeki hassasiyetin tamamen iyileştiği görülmüştür. Hiçbir hastada ise post-operatif amfizem ile karşılaşılmamıştır.

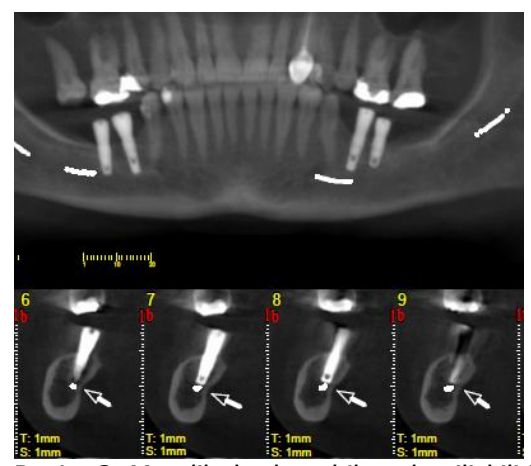

Resim 3. Mandibular kanal ile yakın ilişkili implant yerleşimi sonucu postoperatif his kaybı

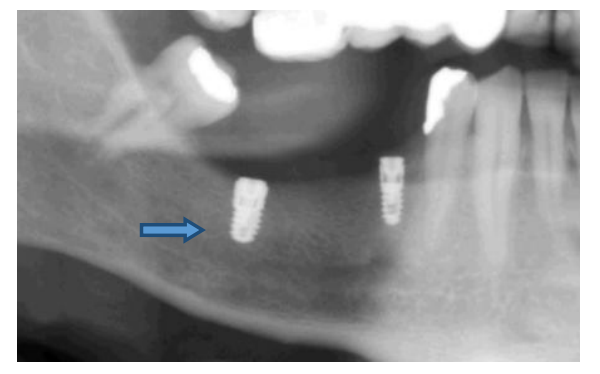

Resim 4. Frezleme sırasında mandibular kanala girilmesi sonrası kısa implant yerleştirilmesi

\section{TARTIŞMA}

Dental implant cerrahisinde karşılaşılan komplikasyonlar ve tedavileri ile ilgili literatürde birçok çalışma bulunmaktadır. Çalışmalarda komplikasyonlar aynı başıklar altında olmasına rağmen farklı sınıflamalara dahil edilmiştir. Ancak tüm bu komplikasyonlar, sayıları ve oranları bütün olarak değil her bir komplikasyon türü için ayrı ayrı değerlendirilmiştir. ${ }^{7,10,12,13}$ Bu bağlamda çalışmamızda karşılaşılan implant komplikasyonlarının sayıları, oranları ve tedavi seçenekleri her bir başlık altında ayrı ayrı değerlendirilerek bu şekilde ele alınmıştır.

Cerrahi işlemler sırasında kontüzyon, abrazyon ve laserasyonlar meydana gelebilmektedir. Bunun nedeni cerrahi aletlerin uygunsuz kullanımdan kaynaklanan yumuşak doku yaralanmalarıdır. Flep laserasyonları da yumuşak doku travmalarına dahil edilmektedir. Kontüzyon ve abrazyonlar tedavi gerektirmezken laserasyonlar sonucu oluşan yaralanmalar suture 
edilmelidir. ${ }^{4}$ Literatürde yumuşak doku yaralanmaları üzerine prevelans verisi ile karşılaşılmamakla birlikte çalışma hastalarımızda \%4,3'lük bir kompli- kasyon oranı elde edilmiştir.

Cerrahi prosedürler kapsamındaki kanama durumu; yumuşak doku yönetimi, bölgenin anatomisi ve hastanın sistemik durumu(Hipertansiyon, antikoagülan kullanımı vb.) gibi değişkenlere bağlıdır. Bu değişkenlere göre sadece cerrahi prosedürlere bağlı kalarak implant cerrahisi esnasında meydana gelebilecek kanama miktarını tahmin etmek mümkün değildir. Oluşan kanamanın miktarına göre hemorajik sorunlar; peteşi, purpura, ekimoz ve hematom olarak tiplendirilir.7 Olası intraoperatif kanama nedenleri arasında yumuşak dokudaki arterlerin insizyonu, dikkatsiz osteotomi ve açık sinüs lift işlemi sırasında lateral sinüs duvarının kaldırılması prosedürleri yer alır. ${ }^{9}$ Hemoraji ile ilişkili implant komplikasyonlarının prevelansı \%12 ile \%30 arasında değişmekte olup, farklı çalışmalar incelendiğinde toplam 379 hastada ortalama \% 24 oranında bulunmuştur. ${ }^{14-16}$ İntraoperatif kanamalarda; kemik mumu, basınçlı tampon, kemiği ezme ve yumuşak dokuda elektrokoter kullanımı veya damarları bağlamak kanamayı durdurmaya yarayacak yöntemlerdendir. ${ }^{6,}$ 17, 18 Sonuç olarak; bu yöntemler ile çalışmada karşılaşılan kanama komplikasyonunda olduğu gibi hem kanama kontrolü sağlanır hem de buna bağlı olarak gelişebilecek ekimoz ve hematomun önüne geçilmiş olur.

Hemoraji sonucu oluşan ekimoz ve hematomun nedeni kanın cilt altında toplanmasıdır. Ekimozun cerrahi bölgede görülmesinin dışında yer çekiminin etkisiyle de mandibula alt sınırı, çene altı, boyun ve göğüste de görülebilmektedir. Herhangi bir tedavi gerekmez. Hematom ise daha çok cerrahi bölgede görülür. Enfekte olmadığı veya oluştuğu bölgeye bağlı olarak yaşamsal fonksiyonlarda sorun yaratmadığı sürece tedavi gerektirmez. Yaşamsal fonksiyonları engelleyen durumlarda hematomun drenajı sağlanmaIıdır. ${ }^{7}$ Çalışmamızda antikoagülan kullanan ve anamnezinde belirtmeyen hastada postoperatif hematom ile karşılaşılmış olup hasta hospitalize edilerek kanama kontrolü ve hasta takibi gerçekleştirilmiştir.

Cerrahi işlemler sırasındaki komplikasyonlar ve cerrahi işlemin agresifliği oluşan ödem miktarı üzerine etkilidir. İşlem ne kadar agresif veya büyükse ortaya çıkan prostoglandinler ve ağrı mediatörleri daha fazla olur. Sonuç olarak da ödem miktarı artmış olur. ${ }^{19} \mathrm{Bu}$ nedenle çalışmada implant hastaları tek seansta 3 implanttan fazla ve 3 implant ve altında olmak üzere iki gruba ayrıldı. 3'ten fazla implant yapılan hastalarda ödem oluşma prevelansı daha yüksek bulunmuştur. Oral cerrahiler sonrası postoperatif 1 . ve 2. günlerde ödem en üst seviyeye çıkar ve 3 . günden sonra azalmaya başlar. Ödem için herhangi bir tedavi gereksinimi bulunmamaktadır. ${ }^{20-22}$

İmplant cerrahilerinden sonra nörosensoryal değişiklikler meydana gelebilmektedir. ${ }^{23}$ Osteotomi sırasında inferior alveoler kanal veya mental foramen içine girilebilir ve sonucunda sinirde kontüzyon, transeksiyon veya laserasyon meydana gelebilir. Ayrıca implant yerleştirildiği sırada apikaldeki kemiğin itilmesiyle kanal içindeki sinirin sıkışmasına neden olunabilir. ${ }^{24}$ Ek olarak yumuşak doku içerisindeki lingual veya mental sinir kompresyon, ekartasyon, insizyon veya iğne penetrasyonu sonucunda zedelenebilir. ${ }^{25}$ Sinir yaralanmalarından sonra hastalarda bazı semptomlar ortaya çıkar: Parestezi(Uyuşukluk hissi, yanma, karıncalanma), hipoestezi( Azalmış duyu fonksiyonu), hiperestezi( Artmış hassasiyet), diestezi (Ağrı oluşması) veya anestezi (Tam duyu kaybı). ${ }^{26}$

Bartling ve ark. ${ }^{8}$, mandibulaya toplam 405 tane implant yerleştirdikleri 94 hastayı nörosensoryal değişiklikler açısından 6 ay boyunca takip etmişlerdir. Ameliyat sonrası ilk randevuda hastaların \%8,5'inde nörosensoryal değişiklikler görülmüştür. Aralarında sadece bir hastada tam anestezi yaşanmıştır ve 4 ay sonunda tamamen iyileşmiştir. Altı aylık çalışmanın sonunda hastaların hiçbirinde kalıcı değişim kalmamıştır. Van Steenberghe ve ark. ${ }^{15}$, mandibulaya implant uygulandıktan sonra yapılan 1 yılık takiplerde nörosensoryal değişikliklerde $\% 6,5^{\prime}$ lik bir oran görmüşlerdir. Diğer bir çalışmada Ellies ve Hawker ${ }^{27}$, \%36 oranında nerosensöryal değişiklik oranı görmüş olup bu hastaların \%10-\%15'inde hiçbir zaman tam olarak tekrar duyu kazanımı olmadığını ifade etmişlerdir. Goodacre ve ark. ${ }^{9}$, implant uygulaması sonrası nörosensoryal değişikliklerin prevelansı için 11 adet çalışmayı değerlendirmişlerdir. Toplam 2142 hastanın 151 'inde ameliyat sonrası değişiklik görülmüştür. Çalışmalarda \%0,6 ile \%39 arasında olan his kaybının ortalaması \%7'dir. Dört farklı çalışmada da 1 yıl sonundaki takiplerde his kaybının azaldığı gösterilmiştir. Beş yılın sonunda ise küçük bir grup hastada kalıcı semptomlar bulunmuştur.

Nörosensoryal komplikasyonlardan kaçınmak için implant yerleştirilmeden önce uygun tedavi planlaması ve uygun radyografi değerlendirilmesi yapılma-

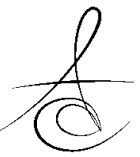


Iıdır. Mandibular kanal radyografide görülmüyorsa bilgisayarlı tomografiden faydalanılmalıdır. Bütün hepsi eksiksiz gerçekleştirilse bile muhtemel komplikasyonlar için hastadan aydınlatıımış onam mutlaka alınmalıdır. ${ }^{10}$ Tüm önlemlere rağmen işlem sırasında frezin veya implantın mandibular kanala veya mental foramene düştüğü hissedilirse veya şüphe duyulursa radyografi alınıp kontrol edilmelidir. Eğer durum böyle ise implant çıkarılıp yerine daha kısa bir implant yerleştirilmelidir. Küçük sinir yaralanmaları zaman içerisinde genellikle iyileşir ancak nörit nedeniyle kalıcı hasar oluşabilir. Sinir iyileşmesini desteklemek ve semptomları azaltmak için hastalara klonazepam, karbamezapin veya vitamin B kompleksi reçete edilebilir. ${ }^{10,28}$ Sinir yaralanmaları için cerrahi düşünülüyorsa tedavi, hasarın distalindeki sinirlerin dejenerasyonundan önce gerçekleştirilmelidir. ${ }^{26}$

Nasal kavite ve sinüs perforasyonları implant öncesi cerrahi hazırlıklar (Açık veya kapalı sinüs lift) sırasında veya implant yuvaları hazırlanırken frezin ve implantın yanlış kullanımı sonucu oluşabilir. Bu perforasyonlar ciddi sonuçlara neden olmazlar. Böyle durumlarda mukoza sağlamsa seçilenden daha uzun bir implant kullanılıp mukoza kaldırılarak çatı oluşturulur ve oluşan boşluk içinde pıhtı birikerek sinüs tabanında kemikleşme sağlanır. Eğer mukozada küçük bir perforasyon meydana geldiyse planlanandan daha kısa bir implant kullanılabilir. Eğer büyük bir perforasyon varsa ya işlem yarıda kesilir ya da perforasyon alanı membran ile kapatılarak implantlar yerleştirilir. ${ }^{4}$ İmplantların primer stabilizasyonu iyi değilse perforasyon halinde implantların nasal kaviteye ve sinüs içine migrasyonu mümkündür. Bu durumda implantların cerrahi veya endoskopik olarak çıkarılması gerekmektedir. ${ }^{29}$ İmplant cerrahisi ve implant öncesi hazırlık aşamasında karşılaşılan komplikasyon oranları $\% 35$ ile \%44 arasında değişiklik göstermektedir. ${ }^{30}$ Yeterli kemiğin bulunduğu durumlarda perforasyonlar sorun oluşturmaz. Hatta implantın birkaç milimetre sinüs veya nasal kavite boşluğuna yerleştirilmesi genellikle iyi tolere edilir. Ancak bu durumlarda antibiyoterapi ve dekonjestan rejimi başlanmalıdır. ${ }^{7}$

Dehissensler ve fenestrasyonlar yetersiz kemik genişliği olan kretlerde veya frezleme ve implant yerleştirilmesi sırasında yapılan hatalardan kaynaklı meydana gelen alveoler kret defektleridir. Defektler sonucunda implantın kemik içindeki desteği azalır ve fonksiyon sırasında kemik desteği ve implant kaybına neden olabilir. Ayrıca açığa çıkan yivler yumuşak dokuda da travmaya neden olabilmektedir. ${ }^{31,32}$ Komplikasyon oluşur oluşmaz primer stabilite sağlandığı sürece implant yerleşimini takiben membran kulanılarak veya kullanılmadan defektler derhal greftlenmelir. Bu komplikasyondan kaçınmak için dar kretlerde flepsiz implant cerrahilerinden kaçınılmalıdır. ${ }^{10}$ Literatür incelendiğinde implant cerrahisi sırasında oluşan bu tür defektlerle ilgili herhangi bir prevelans çalışması ile karşılaşılmamıştır ve çalışmamızda \%2'lik bir oran elde edildiği görülmüştür.

Başka bir intraoperatif komplikasyon ise komşu dişe hasar verilmesidir. İmplantın komşu dişe paralelliği sağlanmazsa frezleme esnasında dişe hasar verilebilir veya implantlar dişe fazla yakın olursa da benzer semptomlar oluşur. Bundan kaçınmak için doğru açılama yapılmalı ve komşu dişlerle olan mesafe en az 1,5 milimetre olmalıdır. Travmanın derecesine göre etkilenen dişin takibi, kanal tedavisi, apikal cerrahisi veya çekimi gerçekleştirilebilir. ${ }^{11}$ Çalışmamızda komplikasyon sonucu etkilenen dişlere kanal tedavileri gerçekleştirilerek tedavi edilmiştir.

İmplant cerrahisi enstrümanlarının ve implant parçalarının kırılması, yutulması ve aspire edilmesi nadir karşılaşılan komplikasyonlardandır. Literatürde bu tür olaylara dair az sayıda rapor bulunmaktadır. Aletler, malzemedeki üretim hataları veya uzun süre kullanım ve çok sayıda sterilizasyon sonrası yıpranması nedeniyle kırılabilir. Bir alet kırıldığında intraoperatif radyografiler yardımıyla lokalize edilip çıkarılmalıdır. ${ }^{4}$ Dental malzemelerin ve implant parçalarının yutulması ve aspirasyonu ise hayatı tehdit eden bir komplikasyon yaratabilir. Genellikle yabancı bir cisim aspire edildiğinde duruma öksürük eşlik eder. Ancak öksürük semptomu olmadan da aspirasyonu meydana gelmiş olabilir. Böyle bir durumda hasta acil olarak göğüs cerrahına yönlendirilmelidir. ${ }^{33,34}$

Yerleştirilen implantın primer stabilitesinin olmaması implant başarısı açısından ele alınması gereken önemli bir komplikasyondur. Primer stabilite kaybı yaşanan implant çıkarılmalı ve yerine daha geniş çaplı bir implant yerleştirilmelidir. Müdahale edilmeyen implantın etrafında fibröz bir kapsül oluşabilir ve implant kaybı gerçekleşir. ${ }^{35} \mathrm{Bu}$ nedenlerden dolayı çalışmada primer stabilite kaybı yaşanan implant operasyon sırasında daha büyük çaplı bir implant ile değiştirilmiştir. 
Oral cerrahilerden sonra yumuşak ve sert dokuyu ilgilendiren enfeksiyonların gerçekleşebileceği her zaman akılda tutulmalıdır. ${ }^{36}$ Çeşitli oral cerrahilerden sonra enfeksiyon oranı \%1'den \%5,4'e kadar değişmektedir. Aynı çalışmalarda preoperatif, intraoperatif ve postoperatif antibiyoterapi almayan hastalarda enfeksiyon oranı $\% 2,33$ ile $\% 5,4$ olarak bulunmuştur. ${ }^{37,} 38$ İmplant tedavilerinden sonra enfeksiyon gelişme oranını Powell ve ark. ${ }^{39} \% 1,14$, Gynther ve ark. $^{40}$ ise $\% 0,7$ olarak tespit etmişlerdir. Günümüzde implant cerrahisinde enfeksiyon kontrolü açısından uygun olan, prosedürden 2 saat önce 2 gram amoksisilin profilaksisi uygulanmasıdır. ${ }^{41}, 42$ Dental implantların yerleştirilmesi sonrası oluşan enfeksiyonların tedavi prensipleri diğer dentoalveoler cerrahilerle aynıdır. ${ }^{36}$ İmplant cerrahileri sonrası tedavi edilmeyen enfeksiyonlar nekrotizan mediastinit tablosuna kadar ilerleyebilen ağır komplikasyonlara neden olabilirler. ${ }^{43}$ Meydana gelen dental implant enfeksiyonlarının tedavisinin antibiyoterapi rejimi olduğu gösterilmiştir. ${ }^{44}$ Çalışmamızda değerlendirilen 498 implant için enfeksiyon oranı $\% 1,6$ olarak tespit edilmiş olup vakalar antibiyoterapi ile tedavi edilmiştir.

Oral cerrahilerde doku amfizemi cilt ve mukoz membranların altına hava birikmesi sonucu oluşur. Bunun nedeni çoğunlukla hava ile çalışan turlar ve enjektörlerdir. Cilt altındaki hava fasya tabakaları arasında ilerleyebilir ve tüm yüze ve submandibular alana yayılabilir. ${ }^{45}$ Bulguları yüzde şişlik ve palpasyonda krepitasyondur. Krepitasyon bulgusu amfizem için patognomoniktir ve ağrı enfekte olmadığı sürece eşlik etmez ${ }^{46}$ Literatürde implant cerrahileri sırasında oluşan amfizem sınırlı sayıdadır. Tedavisi antibiyoterapi, analjezik ve yakın takipten oluşmaktadır. ${ }^{7}$

Cerrahi sonrası flep primer kapatıldıktan 10 gün içerisinde insizyon hattı açılabilir. Böyle bir durumda doku sekonder olarak iyileşmeye devam eder. ${ }^{47}$ Dental implant cerrahilerinden sonra en fazla karşılaşılan komplikasyonlardan biridir. ${ }^{48}$ Operasyon sonrası flep açılması oranı yapılan çalışmalarda $\% 4,6^{49}$ ile $\% 13,7^{50}$ aralığındadır. Yaptığımız çalışmada toplam 258 flep arasında \%1,1 komplikasyon oranı tespit edilmiştir. Etyolojisine bakıldığında enfeksiyon, özensiz atılan suturlar, flebin gergin kapatılması, kötü flep tasarımı ve immediyat implant uygulamaları sayılabilir. Tedavisi açısından literatürde iki farklı görüş bulunmaktadır. Birincisi, açılan bölgeye debridman yapıp antiseptik gargaralarla sekonder iyileşmeye bırakmaktır. İkincisi ise yara kenarlarını bistüri ile deepitelize ederek yeniden suture etmektir. Enfeksiyonu önleme ve implant başarısını arttırma açısından ikinci tedavi seçeneği daha başarııdır. ${ }^{47}$

\section{SONUÇ}

Dental implant cerrahileri her zaman komplikasyona açık küçümsenmemesi gereken cerrahilerdir. Çoğu zaman hayatı tehdit etmeyen komplikasyonlar olsa bile karşılaşılan komplikasyonlar dikkate alınmalı ve hemen müdahale edilmelidir. Bu komplikasyonlar yanlış tedavi tekniklerine ve yetersiz tecrübeye bağı olarak iyatrojenik nedenli olabilmesinin dışında hasta kaynaklı da (Anatomik varyasyonlar, hastanın tedavi esnasında ve iyileşme periyodunda koopere olmaması vb.) gerçekleşebilmektedir. Sonuç olarak komplikasyonsuz ve başarılı bir implant tedavisi için; iyi bir anamnez, doğru tedavi planlaması, uygun hasta seçimi ve yeterli komplikasyon yönetebilme bilgisi ve becerisi gerekmektedir.

Gelengül Urvasızoğlu:ORCID ID: 0000-0003-1628-7571 Tuğrul Türen: ORCID ID: 0000-0002-1199-4122

\section{KAYNAKLAR}

1. Adali E, Yüce MÖ, Günbay $T$, Çiplak G. Farkli Dental İmplantlarin Başari Oranlarinin Geriye Dönük Olarak Değerlendirilmesi. Atatürk Üniv Diş Hek Fak Derg 2018;28:174-81.

2. Alhassani AA, AlGhamdi AST. Inferior Alveolar Nerve Injury in Implant Dentistry: Diagnosis, Causes, Prevention, and Management. J Oral Implantol 2010;36:401-7.

3. McDermott NE, Chuang SK, Woo VV, Dodson TB. Complications of dental implants: identification, frequency, and associated risk factors. Int J Oral Maxillofac Implants 2003;18:848-55.

4. Annibali S, Ripari M, La Monaca G, Tonoli F, Cristalli MP. Local accidents in dental implant surgery: prevention and treatment. Int $\mathrm{J}$ Periodontics Restorative Dent 2009;29:325-31.

5. Balshi TJ. Preventing and resolving complications with osseointegrated implants. Dent Clin North Am 1989;33:821-68.

6. Park S-H, Wang H-L. Implant Reversible Complications: Classification and Treatments. Implant Dent 2005;14:211-20. 
7. Greenstein G, Cavallaro J, Romanos G, Tarnow D. Clinical recommendations for avoiding and managing surgical complications associated with implant dentistry: a review. J Periodontol 2008;79:1317-29.

8. Bartling R, Freeman $K$, Kraut RA. The incidence of altered sensation of the mental nerve after mandibular implant placement. J Oral Maxillofac Surg 1999;57:1408-10.

9. Goodacre CJ, Bernal G, Rungcharassaeng K, Kan JY. Clinical complications with implants and implant prostheses. J Prosthet Dent 2003;90:121-32.

10. Misch K, Wang H-L. Implant surgery complications: etiology and treatment. Implant Dent 2008;17:159-68.

11. Kim SG. Implant-related damage to an adjacent tooth: a case report. Implant Dent 2000;9:278280.

12. Hanif A, Qureshi S, Sheikh Z, Rashid H. Complications in implant dentistry. Eur J Dent 2017; 11:135-40.

13. Berglundh T, Persson L, Klinge B. A systematic review of the incidence of biological and technical complications in implant dentistry reported in prospective longitudinal studies of at least 5 years. J Clin Periodontol 2002;29:197-212.

14. Johns RB, Jemt $T$, Heath MR, Hutton JE, McKenna S, McNamara DC, van Steenberghe D, Taylor R, Watson RM, Herrmann I. A multicenter study of overdentures supported by Brånemark implants. Int J Oral Maxillofac Implants 1992;7:98-114.

15. van Steenberghe D, Lekholm U, Bolender C, Folmer T, Henry P, Herrmann I, Higuchi K, Laney W, Lindén $U$, Åstrand $P$. The Applicability of Osseointegrated Oral Implants in the Rehabilitation of Partial Edentulism: A Prospective Multicenter Study on 558 Fixtures. Int J Oral Maxillofac Implants 1990;5:272-81.

16. Jemt $T$, Laney WR, Harris $D$, Henry $P J$, Krogh Jr $\mathrm{PH}$, Polizzi G, Zarb GA, Herrmann I. Osseointegrated implants for single tooth replacement: a 1-year report from a multicenter prospective study. Int J Oral Maxillofac Implants 1991;6:24-37.

17. Isaacson TJ. Sublingual hematoma formation during immediate placement of mandibular endosseous implants. J Am Dent Assoc 2004;135: 168-72.
18. Pelayo JL, Diago MP, Bowen EM, Diago MP. Intraoperative complications during oral implantology. Med Oral Patol Oral Cir Bucal 2008;13:E239-43.

19. Garcia AG, Sampedro FG, Rey JG, Torreira MG. Trismus and pain after removal of impacted lower third molars. J Oral Maxillofac Surg 1997;55:12236.

20. Graziani F, D'aiuto F, Arduino PG, Tonelli M, Gabriele M. Perioperative dexamethasone reduces post-surgical sequelae of wisdom tooth removal. A split-mouth randomized double-masked clinical trial. I nt J Oral Maxillofac Surg 2006;35:241-6.

21. Üstün $Y$, Erdoğan Ö, Esen E, Karsli ED. Comparison of the effects of 2 doses of methylprednisolone on pain, swelling, and trismus after third molar surgery. Oral Surg Oral Med Oral Pathol Oral Radiol Endod 2003;96:535-9.

22. Micó-Llorens J, Satorres-Nieto M, Gargallo-Albiol J, Arnabat-Domínguez J, Berini-Aytés L, Gay-Escoda C. Efficacy of methylprednisolone in controlling complications after impacted lower third molar surgical extraction. Eur J Clin Pharmacol 2006; 62: 693-8.

23. Greenstein G, Tarnow D. The mental foramen and nerve: clinical and anatomical factors related to dental implant placement: a literature review. J periodontol 2006; 77: 1933-43.

24. Flanagan D. Delayed onset of altered sensation following dental implant placement and mental block local anesthesia: A case report. Implant Dent 2002; 11: 324-30.

25. Day R. Diagnosis and treatment of trigeminal nerve injuries. J Calif Dent Assoc 1994; 22: 4851,53

26. Kraut RA, Chahal O. Management of patients with trigeminal nerve injuries after mandibular implant placement. J Am Dent Assoc 2002;133:1351-1354.

27. Ellies LG, Hawker PB. The prevalence of altered sensation associated with implant surgery. Int J Oral Maxillofac Implants 1993; 8: 14-25.

28. Nazarian Y, Eliav E, Nahlieli O. Nerve injury following implant placement: prevention, diagnosis and treatment modalities. Refu'at ha-peh vehashinayim 1993;20:44-50.

29. Ueda M, Kaneda T. Maxillary sinusitis caused by dental implants: report of two cases. J Oral Maxillofac Surg 1992;50:285-7. 
30. Schwartz-Arad D, Herzberg R, Dolev E. The prevalence of surgical complications of the sinus graft procedure and their impact on implant survival. J Periodontol 2004;75:511-6.

31. Hermann J, Buser D. Guided bone regeneration for dental implants. Current Opinion periodontol 1996;3:168-77.

32. Esposito M, Grusovin MG, Worthington $H$, Coulthard $\mathrm{P}$. Interventions for replacing missing teeth: bone augmentation techniques for dental implant treatment. Austral Dent J 2006;51:96.

33. Bergermann M, Donald PJ. Screwdriver aspiration: a complication of dental implant placement. Int J Oral Maxillofac Surg 1992;21:339-41.

34. Ireland A. Management of inhaled and swallowed foreign bodies. Dent Update 2005;32:83-89.

35. Lioubavina-Hack N, Lang NP, Karring T. Significance of primary stability for osseointegration of dental implants. Clin Oral Implants Res 2006;17:244-50.

36. Bowen Antolín A, García P, Tersa M, Nasimi A. Infections in implantology: from prophylaxis to treatment. Med Oral Patol Oral Cir Bucal 2007; 12: 323-30.

37. Pack PD, Haber J. The incidence of clinical infection after periodontal surgery: A retrospective study. J Periodontol 1983;54:441-3.

38. Checchi L, Trombelli L, Nonato M. Postoperative infections and tetracycline prophylaxis in periodontal surgery: a retrospective study. Quintessence Int 1992;23:191-5.

39. Powell CA, Mealey BL, Deas DE, McDonnell HT, Moritz AJ. Post-surgical infections: prevalence associated with various periodontal surgical procedures. J Periodontol 2005;76:329-33.

40. Gynther GW, Köndell PÅ, Moberg L-E, Heimdahl A. Dental implant installation without antibiotic prophylaxis. Oral Surg Oral Med Oral Pathol Oral Radiol Endod 1998;85:509-11.

41. Binahmed A, Stoykewych A, Peterson L. Single preoperative dose versus long-term prophylactic antibiotic regimens in dental implant surgery. Int J Oral Maxillofac Implants 2005;20:115-117.

42. Hossein K, Dahlin C, Bengt A. Influence of different prophylactic antibiotic regimens on implant survival rate: a retrospective clinical study. Clin Implant Dent Related Res 2005;7:32-5.

43. Marty-Ané $C-H$, Berthet J-P, Alric $P$, Pegis J-D, Rouvière $P$, Mary $H$. Management of descending necrotizing mediastinitis: an aggressive treatment for an aggressive disease. Annals Thoracic Surg 1999; 68: 212-7.

44. Heitz-Mayfield $\quad$, Lang NP. Antimicrobial treatment of peri-implant diseases. Int J Oral Maxillofac Implants 2004; 19: 162-8.

45. Reznick JB, Ardary WC. Cervicofacial subcutaneous air emphysema after dental extraction. J Am Dent Assoc 1990; 120: 417-9.

46. Finlayson RS, Stevens FD. Subcutaneous facial emphysema secondary to use of the Cavi-Jet. J Periodontol 1988; 59:315-7.

47. Sadig W, Almas K. Risk factors and management of dehiscent wounds in implant dentistry. Implant Dent 2004;13:140-7.

48. Giglio J, Laskin D. Perioperative errors contributing to implant failure. Oral Maxillofac Surg Clin North Am 1998; 10: 197-202.

49. Adell R, Lekholm U, Rockler B, Brånemark $P$, Lindhe J, Eriksson B, Sbordone L. Marginal tissue reactions at osseointegrated titanium fixtures:(I). A 3-year longitudinal prospective study. Int J Oral Maxillofac Surg 1986; 15: 39-52.

50. Tal H. Spontaneous early exposure of submerged implants: I. Classification and clinical observations. J Periodontol 1999;70:213-9.

\section{Yazışma Adresi}

Dr Öğretim Üyesi Gelengül Urvasızoğlu Atatürk Üniversitesi Diş Hekimliği Fakültesi Ağız Diş Ve Çene Cerrahisi AD, Erzurum E-mail: gelengul2568@hotmail.com 